\title{
O QUE O KAFFEE DE LÁ TEM QUE O CAFÉ DAQUI NÃO TEM: UM ESTUDO COMPARATIVO ENTRE OS SISTEMAS AGROINDUSTRIAIS DO CAFÉ ALEMÃO E BRASILEIRO
}

\author{
WHAT KAFFEE HAS THERE AND DOES NOT HAVE HERE: A \\ COMPARATIVE STUDY OF THE AGROINDUSTRIAL SYSTEMS \\ UNDERLYING THE GERMAN AND BRAZILIAN COFFEE TRADE
}

MARA LUIZA GONÇALVES FREITAS

Especialista em Cafeicultura Empresarial e mestre em Administração, com ênfase em Dinâmica, Estrutura e Coordenação de Cadeias Produtivas pela Universidade Federal de Lavras (UFLA). Docente do curso de Administração pela Fundação Universidade de Gurupi (UNIRG).

Rua Alziro Zarur, 1.133, casa 1, Jardim Tapirapuã

Tangará da Serra - MT - CEP 78300-000

E-mail:adm@marafreitas.adm.br 


\section{RESUMO}

O presente artigo tem por objetivo comparar a estrutura das cadeias agroindustriais do café brasileira e alemã, visando compreender a razão que conduz a Alemanha a deter a liderança na exportação de cafés, em especial os industrializados (descafeinados, torrados em grão e/ou moídos e solúveis), considerando-se que não detém a competência na produção de cafés, que possui o Brasil. Como aporte teórico utilizaram-se as perspectivas oferecidas pelas principais estruturas de coordenação, mais especificamente o supply chain management, netchain, networks e subsistema estritamente coordenado. Como metodologia, utilizou-se a pesquisa documental, combinada com a análise de conteúdo, proposta por Bardin (2000), as quais culminaram na criação de I2 critérios. Esses critérios favoreceram a geração do Mapa de Análise Comparativa entre as Cadeias Agroindustriais do Café Brasileira e Alemã, apresentado nos resultados e análises das informações. O estudo conclui que as duas principais razões que conduzem a Alemanha ao sucesso estão centradas na forte ação estratégica de mercado das suas empresas, coordenado por uma forte governança institucional.

\section{PALAVRAS-CHAVE}

Sistemas agroindustriais; Estruturas de coordenação; Brasil; Alemanha; Café.

\section{ABSTRACT}

This article, a comparison of the structure of the Brazilian and German coffee chains, aims to clarify why Gerwmany is the a leading coffee exportes (mainly with regard to industrizalized items such as roasted beans and ground, instant and decaffeinated products) despite its not being a coffee producer comparable to Brazil. The theoretical base rests on the principal coordination frameworks, specifically supply chain management, netchain, networks and strictly coordinated subsystems. The methodology employed combines documental research and con- 
tent analysis as proposed by Bardin (2000), which led to the creation of twelve criteria. Using these criteria facilitated the generation of a comparative analysis chart, presented when the data are analyzed and conclusions draw regarding the Brazilian and German coffee chains. The study concludes that the two major reasons underlying the success of Germany are the robust market strategies of its firms and the strong institucional guidelines governing their activities.

\section{KEYWORDS}

Agroindustrial systems; Coordination framework; Brazil; Germany; Coffee.

\section{INTRODUÇÃO}

Para que a almejada liderança internacional dos setores produtivos do Brasil seja alcançada, a tese ora defendida pelo mercado é a de que a ação comercial brasileira passe a adotar práticas utilizadas pelos principais mercados industriais do mundo. Essa é uma realidade do sistema agroindustrial do café brasileiro, que busca transitar de um contexto que historicamente privilegia a produção em detrimento da industrialização a um sistema de comercialização de produtos industrializados de modo mais eficiente. Atualmente, o País sustenta estruturas produtivas à montante, perdendo rentabilidade e market-share no mercado internacional de café, que atualmente negocia US\$ Ioo bilhões/ano, conforme dados da Oxfam (2002).

Nesse sentido, a ruptura do paradigma de mero exportador de commodities converge diretamente sobre a forma de pensar o agronegócio café e, respectivamente, nos processos de evolução da ação dos agentes produtivos, em especial a indústria, em relação à ação internacional, a qual ainda não ultrapassa I,2\% do montante comercializado internacionalmente (FREITAS, 2006).

O que torna a Alemanha melhor do que o Brasil em termos de desempenho internacional no mercado de cafés com maior valor agregado? A coordenação institucional, a infra-estrutura (logística e pólos industriais) ou sua natural participação como país membro da União Européia?

Como se trata de um estudo sobre cadeias produtivas, na primeira parte apresenta-se a revisão de literatura, que discorre sobre as principais estruturas de coordenação, em especial o supply chain management, netchain, networks e subsistema estritamente coordenado.

Já na segunda parte, apresentam-se os métodos de pesquisa adotados para a construção deste estudo. Na terceira parte, são exibidos os resultados e discussões do trabalho, seguidos pela parte final, na qual se encontram as conclusões. 


\section{REVISÃO DE LITERATURA}

A evolução tecnológica introduzida pela Revolução Industrial fomentou o ambiente para que os limites das firmas e até mesmo das nações fossem rompidos, mudando o conceito do que até então denominávamos organização (CLEGG; HARDY, I998). Emerge um novo modelo que privilegia conexões entre os agentes produtivos em detrimento do modelo fordista, na expectativa de subsidiar maior competitividade setorial. Organizações se fundem, formam joint-ventures, abrem seus capitais a investidores, na expectativa de que a estrutura unitária dê lugar ao que atualmente se convenciona de alianças estratégicas, redes, cadeias, complexos ou sistemas produtivos (CLEGG; HARDY, I998).

Cada vez mais as organizações buscam o delineamento de uma estratégia competitiva favorável dentro de sua indústria, considerado aqui o conceito porteriano, em função de ser nesse ambiente o locus onde se dá a concorrência (PORTER, I989). Esse espaço, também chamado de ambiente de negócios, pode ser dimensionado por fronteiras, as quais definem se determinada indústria tem sua competitividade limitada ao mercado doméstico ou caracteriza-se plena amplitude de sua ação, por também atuar no mercado externo, podendo ser inclusive um player global (PORTER, I989; JOHANSON; VAHLNE, I986; FREITAS, 2006).

Para maior compreensão sobre os termos mercado e competitividade aos quais se referem neste estudo, lança-se mão da perspectiva oferecida por Harrison e Kennedy (I997). Para os autores, o mercado é definido como um lugar onde todos os atuais e potenciais compradores e vendedores de produtos podem interagir em um lugar e tempo específico, enquanto a competitividade, nesse ambiente, é cunhada como a capacidade de criar e disponibilizar valor e preços iguais ou menores do que os praticados pela concorrência.

Porter (I986) expõe que é a estrutura da indústria que define o nível de concorrência, dado que tem forte influência na determinação das regras competitivas do jogo, assim como as estratégias das empresas participantes desta. A competitividade deixa então de ser avaliada sob a perspectiva neoclássica (HARRISON; KENNEDY, I997) ${ }^{\mathrm{I}}$ e passa a ser observada sob a perspectiva das cinco forças competitivas porterianas (poder de barganha dos fornecedores, ameaças de novos entrantes, rivalidade entre concorrentes, poder de barganha de clientes e ameaças de produtos substitutos). A avaliação dessas forças é fundamental para a análise de concorrência e determinação da cadeia de valores e vantagens competitivas que uma indústria detém (PORTER, I986; I989). O estabelecimento dessas, por sua vez, favorece a visualização dos elos entre os

I Historicamente, os economistas neoclássicos examinam a estrutura da competitividade a partir da relação entre a origem da competitividade e os custos e demandas de estrutura por parte da firma. 
agentes, os quais podem ser demandantes de otimização de processos quanto à coordenação de atividades (PORTER, I989). Tais elos sinalizam a formação de redes de negócios, em que o relacionamento entre firmas se dá por meio de uma conectividade ilimitada e abrangente, inclusive por meio da conexão indireta (BECHTEL; JAYARAM, I998).

A rigor, a conectividade envolve a integração de negócios, por meio do fluxo de informações e materiais ao longo de uma indústria, tanto vertical (supply chain management) (COOPER; LAMBERT; PAGH, I997; COOPER; LAMBERT, 2000) quanto horizontalmente (network e netchain) (CLARO, 2004; LAZZARINI; CHADDAD; COOK, 200I), o que pode ou não redundar em um subsistema estritamente coordenado (ZYLBERSZTAJN; FARINA, I999).

\subsection{SUPPLY CHAIN MANAGEMENT - SCM}

A adequação estratégica tem demandado cada vez mais da indústria um comportamento integrado verticalmente, denominado supply chain. Essa coordenação pode ser definida como o gerenciamento de múltiplos níveis de relacionamento e negócios (COOPER; LAMBERT; PAGH, I997; LAMBERT; COOPER, 2000). Para Bechtel e Jayaram (I998, p. I5), o SCM assemelha-se a um conceito de ecossistema empresarial que envolve a interconectividade entre processoschave dentro e entre firmas.

Por meio do desenvolvimento do SCM, criam-se condições para a agregação de valor aos materiais, com o aumento do fluxo de informações, intensificando as ações de marketing junto ao consumidor (BECHTEL; JAYARAM, I998, p. I9). Esse esforço contribui para a criação de um ambiente de redução de incertezas, tanto por parte dos usuários finais quanto dos vendedores, além do estabelecimento de rotinas de transações e redução do número de contratos entre os agentes, dado o aumento da confiança entre os agentes (COUGHLAN et al., 2002).

Nesse sentido, a cadeia de suprimentos tem se constituído em um importante conceito para a formatação de parcerias, alianças estratégicas e outras relações cooperativas (BECHTEL; JAYARAM, I998). De acordo com Lambert e Cooper (2000, p. 69), todas as firmas participam de uma cadeia de suprimentos, desde a ligada à produção de materiais até o último consumidor. A relação entre elas depende de deterem algum nível de proximidade entre suas atividades, caracterizadas como membros primários e membros secundários.

Para Lambert e Cooper (2000, p. 70), os membros primários são classificados como empresas autônomas ou unidades de negócios individuais responsáveis pela agregação de valor, por meio do gerenciamento ou operacionalização da comercialização de um produto específico para um cliente ou mercado espe- 
cífico. Os membros secundários são as empresas responsáveis pela geração dos recursos, conhecimentos, utilidades, patrimônio demandados pelos membros primários do canal (LAMBERT; COOPER, 2000).

A coordenação, nesse caso, é classificada pela literatura como uma estrutura de canal verticalizada, cujo nível dependerá da maior proximidade e o número de agentes envolvidos. Em ambientes verticalizados, de acordo com Machado (I998, p. 67), a coordenação permite arranjos econômicos/institucionais, geradores de transferência de recursos, seja por meio do mercado spot, integração vertical de estágios tecnologicamente separáveis em uma mesma firma ou ainda por estabelecimento de contratos formais (parcerias, franchising, licenciamento, entre outros).

De posse dessa organização em nível vertical, torna-se possível a integração horizontal entre diversos estratos de cadeias de suprimentos, ou seja, relações comuns entre fornecedores de uma categoria de matéria-prima, industriais de determinado produto, distribuidores e consumidores (LAZZARINI; CHADDAD; COOK, 200I; CLARO, 2004). Na literatura a conectividade entre os agentes, tanto vertical quanto horizontalmente, recebe o nome de network, definida por Claro (2004, p. 36) como um conceito que se refere às relações interorganizacionais de firmas que possuem funções semelhantes no mercado. Esse conceito é entendido pelo autor como análogo à perspectiva apresentada no modelo de netchain analysis, proposto por Lazzarini, Chaddad e Cook (200I).

A evolução do ambiente institucional conduziu também a evolução do modo de transacionar entre os diversos agentes ao longo de uma estrutura vertical e horizontal. As conexões passaram a ser permeadas por contratos, visando a redução das incertezas e assimetria de informações, bem como agilidade por meio da especificação de ativos e aumento da freqüência nas relações ex-ante e ex-post. A nova conjuntura conduziu a modos de governança (mercado, hierarquia e híbrido) compatíveis com o nível de competitividade de cada mercado. Essa estrutura emerge ante uma necessidade de inserção de tecnologias e criação de salvaguardas e barreiras à entrada a concorrentes, conduzindo a aglutinação de firmas com mesmos interesses, seja em formato de redes ou clusters, aperfeiçoados pelo nível de relacionamento entre os agentes (COASE, I99I; WILLIAMSON, I983, I989, I99Ia, I99Ib, I996, 2000, 2005; RIORDAN; WILLIAMSON, I985).

O network e o netchain podem ser considerados uma sofisticação do SCM, em função deste enfatizar regras de gerenciamento distintas do fluxo de materiais, informações e decisões (LAZZARINI; CHADDAD; COOK, 200I): o network centra-se no relacionamento e o netchain na interdependência em determinado nível e na determinação de estratégias interorganizacionais (CLARO, 2004; LAZZARINI; CHADDAD; COOK, 200I). 


\subsection{NETWORKS, NETCHAIN E SUBSISTEMA ESTRITAMENTE COORDENADO}

A intensa evolução tecnológica, registrada ao longo do último quarto de século, provocou mudanças profundas no comportamento de indivíduos, firmas, instituições e nações, dado o maior fluxo de informações, organização da escala de produção (global) e, principalmente, a interação entre redes empresariais (CASTELLS, I999, p. II9). Essas redes geram, de acordo com Claro (2004, p. I7), importantes implicações no relacionamento entre compradores e fornecedores (buyer-supplier), em função da relação direta com o desenvolvimento dos capitais humano e social (inteligência comercial, nível educacional, socialização, competências essenciais, emoções, monitoramento). Granoveter (I973), citado por Claro (2004, p. I8) define network como

The interpersonal relations that provide diffusion of influence and information, mobility opportunity and community organization. The strength of weak ties is a combination of the amount of time, the emotional intensity, the intimacy and the reciprocal services which characterize the tie.

Ao organizar uma comunidade por meio da informação, cria-se ambiente para a implementação da governança bilateral, embasada na maior mobilidade e nível de colaboração entre os agentes, elevação do nível de responsabilidade e realização de investimentos específicos em transações envolvendo os interesses dos agentes (CLARO, 2004, p. 2I). ${ }^{2}$ A informação gerada em ambiente de cooperação acaba proporcionando alguns benefícios, como, por exemplo, o maior nível de coordenação vertical e horizontal. Nesse sentido, Lazzarini, Chaddad e Cook (200I) propõem o conceito de netchain, como elemento de análise.

Netchain analysis explicitly differentiates between horizontal (transactions in the same layer) and vertical ties (transactions between layers), mapping how agents in each layer are related to each other and to agents in the other layers.

O netchain integra as perspectives propostas pelo SCM e o network por reconhecer as variadas e complexas interconexões existentes nos diversos mecanismos de coordenação e tipos de interdependência - pooled, sequential, reciprocal

2 De acordo com Lazzarini, Chaddad e Cook (200I), são três as competências que originam os valores enfatizados no network: a estrutura social (relacionamento interpessoal dos agentes), o aprendizado (voltado para a criação, inovação, desenvolvimento de oportunidades e co-especialização) e as externalidades do network (geradas dos benefícios proporcionados por meio da adoção de tecnologias ou incremento de contratos). 
(LAZZARINI; CHADDAD; COOK, 200I). As interdependências podem ser traduzidas por meio da forte conexão social e densidade do network e a co-especialização do conhecimento, criando um ambiente de mútuo ajustamento.

Os ajustes conduzem a criação de um supply system, o qual se caracteriza pela mudança de níveis das especificidades dos ativos associadas a diferentes estratégias competitivas que podem afetar as transações através de determinado sistema (ZYLBERSZTAJN; FARINA, I999). Estratégias adquiridas acabam influenciando o comportamento dos agentes presentes em determinado network, como em um netchain. Ao desenvolverem o que Zylbersztajn e Farina (I999) definem como subsistema estritamente coordenado (Figura I), considerada estratégia de diferenciação de um grupo (pool de organizações empresariais e instituições) em um mercado específico em nível vertical, as relações entre agentes presentes no mesmo nível (netchains) também podem sofrer modificações, tanto no âmbito tecnológico, como contratual.

\section{FIGURA I}

\section{SUBSISTEMA ESTRITAMENTE COORDENADO}

$\mathrm{T} 1$

T2

T3

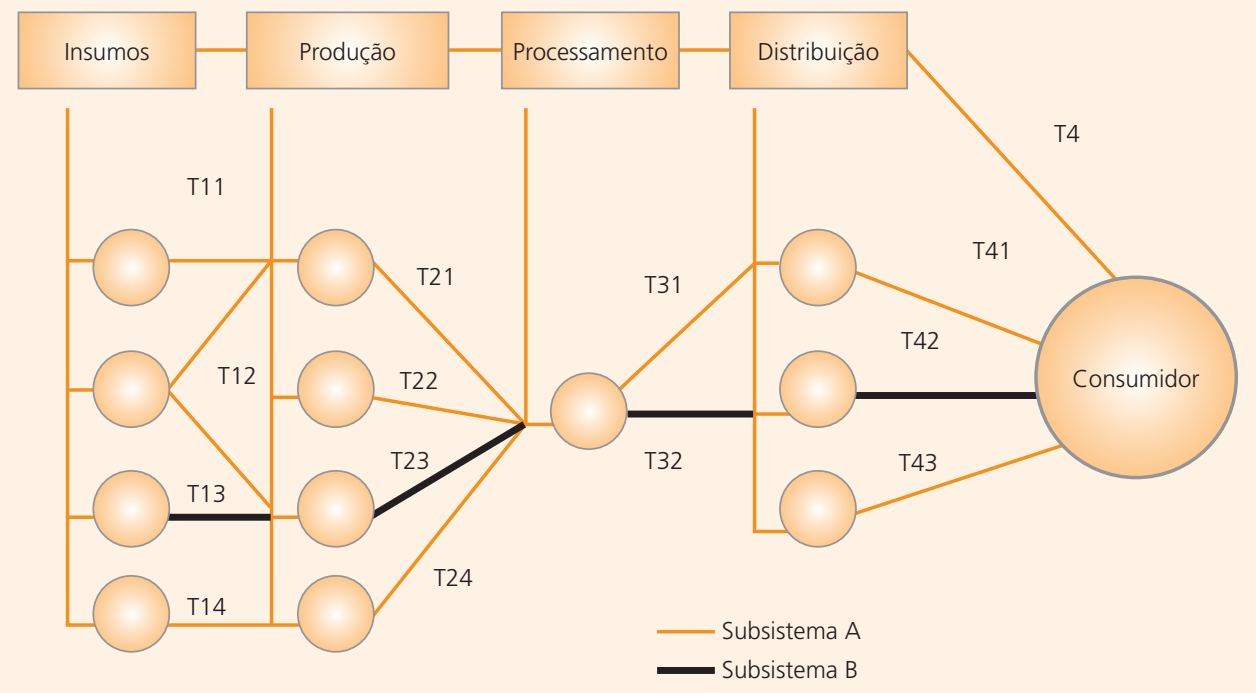

Fonte: Zylbersztajn, Farina (I999).

A perspectiva do subsistema estritamente coordenado é de facilitar a articulação das habilidades entres os agentes sob uma mesma integração vertical, para garantir maior vantagem competitiva em relação a outros subsistemas. Por permearem as 
transações reguladas por contratos, os subsistemas podem contribuir para mudanças importantes no comportamento institucional, por meio de modificações de leis, criação de barreiras de entrada, estabelecimento de relacionamentos bilaterais, definição dos níveis de concorrência (ZYLBERSZTAJN; FARINA, I999).

O modelo apresentado na Figura I, bem como as outras formas de coordenação, auxilia na compreensão dos sistemas agroindustriais, como o do café brasileiro e alemão.

\subsection{SOBRE OS SISTEMAS AGROINDUSTRIAIS}

A coordenação, de acordo com Zajac e Olsen (I993) é uma opção estratégica interorganizacional, envolvendo dois ou mais agentes ao longo de uma cadeia. A adoção de determinada forma de governança, a princípio, depende de qual das formas genéricas de organização econômica (WILLIAMSON, I99Ia, b) norteará a redação dos contratos. A duração desses contratos dependerá da especificidade dos ativos (que pode ser não específico, misto e muito específico), da incerteza e da freqüência (que pode ser única, ocasional ou corrente) e de sua característica: spot, clássica ou neoclássica, as quais possuem estruturas de governança específica (WILLIAMSON, I983). No âmbito dos contratos clássicos, verifica-se que a governança pode acontecer por meio de relações bilaterais ou idiossincrásicas; no caso dos neoclássicos, os contratos são trilaterais.

Zylbersztajn e Farina (I994, p. 4), nesse sentido, definem os sistemas agroindustriais de alimentos e fibras como um nexo de contratos decorrentes do processo de minimização de custos de produção/distribuição e de transação. Os contratos, como visto anteriormente, visam a redução das incertezas, tanto da parte dos usuários finais quanto da parte vendedora. Além de favorecerem o estabelecimento de rotinas de transações e redução do número de contratos entre os agentes, eles impactam diretamente na consolidação dos laços de confiança entre os agentes (COUGHLAN et al., 2002). A compreensão dos nexos de contratos interessa, porque os sistemas agroindustriais apóiam-se em uma cadeia produtiva que compreende os segmentos a montante e a jusante da porteira da fazenda (MACHADO, 2005, p. 49).

A embricação contratual entre agentes ao longo da cadeia produtiva acaba por demandar a presença de organizações e instituições, que contribuam de modo geral para a regulamentação de processos, bem como definição de políticas setoriais, estruturação de estratégias corporativas e governamentais, convergindo para o aumento da competitividade da cadeia (ZYLBERSZTAJN; FARINA, I994). Na Figura 2, apresenta-se um modelo de ambiente de negócios aplicado ao agronegócio.

Nesse modelo, as relações entre os agentes direta e indiretamente envolvidos no sistema agroindustrial são dinâmicas e interdependentes. Como se pode observar, o fundamento do processo centra-se na coordenação vertical entre os 
agentes produtivos, em que acontecem as relações contratuais e a respectiva agregação de valor aos produtos alimentares e fibras. De acordo com Machado (2005), a valorização das relações mais dinâmicas entre os atores conduz a uma maior incorporação de inovações e procedimentos que conduzam a maior competitividade setorial, por meio da redução de custos, diminuição de incertezas e diferenciação de produtos.

\section{FIGURA 2}

\section{O AMBIENTE DE NEGÓCIOS NO CONTEXTO DO AGRONEGÓCIO}

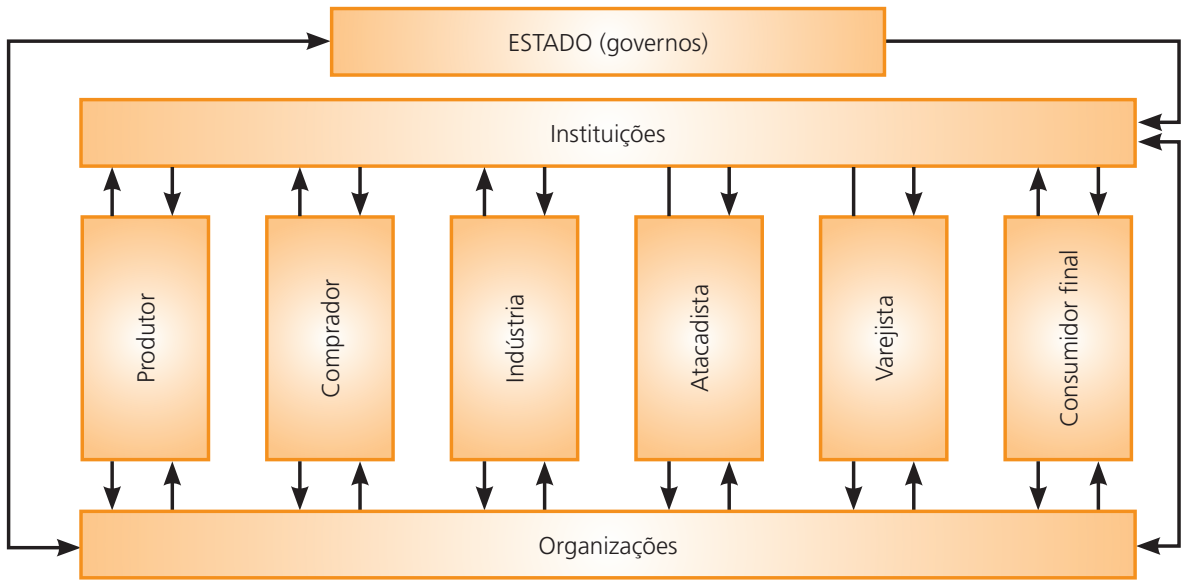

Fonte: Elaborada pela autora, 2006.

As transações estabelecidas entre os agentes produtivos podem ou não sofrer influência das organizações e instituições que compõem determinado sistema agroindustrial. Isso dependerá da capacidade de organização de cada conjunto de agentes pertencente a cada elo produtivo que compõe o sistema agroindustrial. Há o exemplo da criação de sindicatos ou associações de produtores rurais, industriais, atacadistas, varejistas e também de consumidores, em âmbito local ou regional. Cada elo possui necessidades distintas, as quais são discutidas no ambiente das organizações para criar alternativas de difusão de conhecimentos ou tecnologias que impactem diretamente no dia-a-dia do agente. Além disso, ele se presta para a aproximação entre os agentes, de modo que aumente o nível de confiança e reduza assimetrias de informação, conforme anteriormente exposto.

Quando determinado elo possui um volume representativo de organizações e passa a demandar regras para a sua regulamentação ou melhor desempenho de mercado, em âmbito nacional ou internacional, surgem as instituições, difusoras de regras do jogo, que detêm poder de barganha para negociação e defesa de interesses setoriais com o Estado. Nesse âmbito as ações realizadas por insti- 
tuições, normalmente combinadas com aporte legal, exercem influência direta na competitividade do sistema agroindustrial: as instituições passam a criar condições para o desenvolvimento de competências essenciais, economia de escala, otimização da estrutura setorial, pelo maior poder de barganha para alocação de recursos, aporte legal e tecnológico, sendo, portanto, facilitadoras para a criação de uma coleção única de recursos (PRAHALAD; HAMEL, I997; COASE, I99I; WILLIAMSON, I99Ia, b; MACHADO, 2000).

A cadeia agroindustrial do café brasileira nesse sentido apresenta vários exemplos, como o Programa de Marketing dos Cafés do Brasil, coordenado pela parceria entre o Ministério da Agricultura, Pecuária e Abastecimento, e o Grupo Gestor de Marketing, do Conselho Deliberativo de Política Cafeeira (CDPC), conselho formado por representantes do governo e instituições setoriais privadas. Ações realizadas na esfera institucional acabam por influenciar aquelas realizadas na estrutura vertical da cadeia. Uma vez tomada uma decisão nesse foro, imediatamente as organizações ligadas às instituições representantes da indústria e da produção difundem as informações aos produtores e industriais. Indústrias e produtores, por sua vez, adotam procedimentos e ações que permitem a visibilidade da ação pelo consumidor, esteja ele no Brasil ou no Exterior. Ainda que essas ações em nível micro levem algum tempo para serem incorporadas pelo mercado, é inevitável que as incorporações aconteçam, estimuladas pela força institucional, que difunde as regras.

\section{PROCEDIMENTOS METOdOLógicos}

\subsection{CARACTERIZAÇÃO DO TIPO DE PESQUISA}

O presente artigo caracteriza-se por ser um estudo qualitativo, de caráter exploratório-descritivo.

\subsection{ESTRATÉGIA DE PESQUISA E COLETA DE DADOS}

Conforme apresentado anteriormente, o trabalho tem por objetivo comparar a estrutura das cadeias agroindustriais do café brasileira e alemã, visando compreender a razão que conduz a Alemanha a deter a liderança na exportação de cafés, em especial os industrializados (descafeinados, torrados em grão e/ou moídos e solúveis) considerando-se que não detém a competência na produção de cafés, que possui o Brasil.

Em função disso, adotou-se como estratégia, a pesquisa documental e análise de conteúdo, proposta por Bardin (2000), usando as informações disponibilizadas pelas instituições ligadas ao agronegócio café, via internet. 
Lançou-se mão de consultas aos seguintes sites institucionais: I. Deutscher Kaffeeverband (Associação Alemã do Café); 2. Associação Brasileira da Indústria do Café - Abic; 3. Conselho Nacional do Café - CNC; 4. Organização Internacional do Café - OIC; 5. Federação Européia do Café - ECA; 6. Conselho dos Exportadores de Café do Brasil - Cecafé; 7. Centro do Comércio do Café do Rio de Janeiro - CCCRJ; 8. Centro do Comércio do Café de Vitória - CCCV; 9. Centro do Comércio do Café de Minas Gerais - CCCMG; ıo. Associação Comercial de Santos - ACS; iı. Centro de Inteligência do Café - CIC; I2. Ministério do Desenvolvimento, Indústria e Comércio - MDIC.

Foram realizadas leituras sistemáticas dos clippings de notícias das instituições supracitadas, informações sobre a instituição, relação de associados, parceiros, consultas aos links disponibilizados pelos sites. Com base na sistematização dessas leituras, ocorridas entre março de 2004 e julho de 2006 , foi possível elencar I2 critérios de avaliação, apresentados no Quadro I, para facilitar a compreensão da dinâmica dos dois mercados estudados, visando a realização de estudos quantitativos futuros.

\subsection{ANÁLISE DOS DADOS}

As informações foram tratadas por meio do Mapa de Análise Comparativa entre as Cadeias Agroindustriais do Café Brasileira e Alemã, estruturadas com base nos critérios estabelecidos no Quadro I.

No Mapa, o Peso I equivale ao critério favorável ao mercado analisado e o Peso 2, ao critério desfavorável. Utilizaram-se esses pesos para a criação de um gráfico síntese do Mapa de Análise Comparativa.

\section{RESULtAdOS E ANÁLISES}

\section{DA LEITURA DO MAPA DE ANÁLISE COMPARATIVA ENTRE AS CADEIAS AGROINDUSTRIAIS DO CAFÉ BRASILEIRA E ALEMÃ}

Após a sintetização dos dados, efetuou-se sua transferência para o Mapa de Análise, exibido no Quadro 2, que oferece condições para verificação das diferenças estruturais entre o sistema agroindustrial do café brasileiro e alemão. Observando a representação gráfica, em especial da Figura 3, verifica-se maior irregularidade no caso brasileiro. 
Quando se trata da presença de agentes ao longo da cadeia produtiva, o mercado alemão, embora não tenha o elo produtor de café, possui todos os demais agentes elencados no Quadro I da metodologia. O mesmo não acontece quando observada a cadeia agroindustrial do café brasileira. Apesar de não faltar o elo produtor, faltam agentes importantes, quando se trata de processos de industrialização: inexiste o importador de café verde, uma vez que o País não pratica o drawback de café, além de companhias de descafeinização de café. Faltam também companhias produtoras de aromatizantes para café, mas essa seria uma barreira tecnológica relativamente fácil de suprir, por já existirem empresas especializadas em produção de aromatizantes para alimentos instaladas em parques industriais brasileiros.

\section{QUADRO I}

\section{CRITÉRIOS PARA COMPARAÇÃO DAS CADEIAS PRODUTIVAS DO CAFÉ BRASILEIRA E ALEMÃ}

\begin{tabular}{ll}
\hline CRITÉRIO & DESCRIÇÃO DO CRITÉRIO DE COMPARAÇÃO \\
\hline & Existência ou não do agente na cadeia. Quanto mais agentes presentes, mais \\
& completa e mais competitiva a cadeia. Para tal, serão considerados os seguintes \\
& elos: (i) produtores de café; (ii) importadores de café verde; (iii) exportadores \\
Presença de agentes & de café verde; (iv) companhias de descafeinização de café; (v) companhias \\
ao longo da cadeia & de café solúvel; (vi) companhias de café torrado em grão e/ou moído; (vii) \\
produtiva & companhias produtoras de máquinas e equipamentos - café; (viii) companhias \\
& produtoras de aromatizantes - café; (ix) companhias produtoras de embalagens \\
& - café; (x) corretoras credenciadas em bolsas de mercadorias; (xi) laboratórios; \\
& (xii) instituições; (xiii) prestadores de serviços de transporte aéreo, terrestre e \\
& marítimo.
\end{tabular}

Proximidade do suprimento de café Próximo ou não próximo. A proximidade dos insumos contribui para a redução verde com a unidade de de custos importantes, como os de transporte e estocagem.

industrialização

Disponibilidade de tecnologia para modernização de plantas industriais

Disponibilidade de tecnologia de descafeinização e aromatização de café
Existe ou não existe. A disponibilidade de tecnologia para a produção de produtos tecnologicamente compatíveis com a demanda de mercado contribui para que a indústria se torne mais competitiva.

Existe ou não existe. A disponibilidade da tecnologia de descafeinização e aromatização contribui para que as companhias de solubilização e torrefação tenham maior capacidade de atendimento a demandas do mercado consumidor, tanto internas como externas, em função da possibilidade do aumento do seu portfólio de produtos oferecidos. 


\section{QUADRO I (CONTINUAÇÃO)}

\section{CRITÉRIOS PARA COMPARAÇÃO DAS CADEIAS PRODUTIVAS DO CAFÉ BRASILEIRA E ALEMÃ}

\begin{tabular}{|c|c|}
\hline CRITÉRIO & DESCRIÇÃO DO CRITÉRIO DE COMPARAÇÃO \\
\hline $\begin{array}{l}\text { Disponibilidade de } \\
\text { tecnologia para envase e } \\
\text { companhias produtoras } \\
\text { de embalagens }\end{array}$ & $\begin{array}{l}\text { Existe ou não existe. O acesso à tecnologia de envase, bem como a presença } \\
\text { de companhias produtoras de embalagens no mercado, contribui para a } \\
\text { adequação e/ou modernização de sistemas de envase e tipos e formatos de } \\
\text { embalagem. }\end{array}$ \\
\hline $\begin{array}{l}\text { Acesso à negociação em } \\
\text { bolsa de mercadorias }\end{array}$ & $\begin{array}{l}\text { Existe ou não existe. O acesso à negociação em bolsa de mercadorias oferece às } \\
\text { companhias que operam no mercado a oportunidade de realizar tanto compras } \\
\text { de insumos com preços predefinidos, quanto a venda de seus produtos a } \\
\text { futuro. }\end{array}$ \\
\hline $\begin{array}{l}\text { Disponibilidade de } \\
\text { laboratórios para } \\
\text { realização de controle de } \\
\text { qualidade }\end{array}$ & $\begin{array}{l}\text { Existe ou não existe. A disponibilidade de laboratórios que visem a realização } \\
\text { de controle de qualidade dos produtos favorece a manutenção do alto padrão } \\
\text { de qualidade e ao mesmo tempo minimizam os riscos com as barreiras técnicas } \\
\text { internacionais. }\end{array}$ \\
\hline $\begin{array}{l}\text { Prática de importação de } \\
\text { matéria-prima }\end{array}$ & $\begin{array}{l}\text { Pratica-se ou não. A prática da importação de matéria-prima favorece a } \\
\text { ampliação do portfólio de produtos industrializados, tornando-o apto a atender } \\
\text { todos os tipos de consumidores. Além disso, contribui para a redução de } \\
\text { custos, uma vez que se podem adquirir matérias-primas globalmente, bem } \\
\text { como desenvolver sistemas de fornecimento exclusivos, usando suprimentos de } \\
\text { várias partes do mundo. }\end{array}$ \\
\hline $\begin{array}{l}\text { Proximidade das áreas } \\
\text { industriais com áreas } \\
\text { portuárias }\end{array}$ & $\begin{array}{l}\text { Próximo ou não próximo. A proximidade com áreas portuárias favorece não } \\
\text { apenas o escoamento da produção para o mercado internacional, como } \\
\text { também reduz custos de transporte. }\end{array}$ \\
\hline $\begin{array}{l}\text { Instituições responsáveis } \\
\text { pela governança da } \\
\text { cadeia produtiva }\end{array}$ & $\begin{array}{l}\text { Polarizado ou não polarizado. O maior número de instituições representando } \\
\text { mais agentes ao longo da cadeia produtiva exige maior esforço de negociação } \\
\text { institucional antes de as necessidades setoriais serem supridas. }\end{array}$ \\
\hline $\begin{array}{l}\text { Capacidade de } \\
\text { transferência de know- } \\
\text { how para a Organização } \\
\text { Internacional do Café }\end{array}$ & $\begin{array}{l}\text { É difusor ou não de regras compartidas. A Organização Internacional do Café, } \\
\text { em função de sua capilaridade, adota programas bem-sucedidos de alguns } \\
\text { países, tornado-os, como conseqüência, referências. }\end{array}$ \\
\hline $\begin{array}{l}\text { Investimento direto da } \\
\text { indústria nacional no } \\
\text { mercado externo }\end{array}$ & $\begin{array}{l}\text { Possui ou não possui multinacionais com bandeira do país. A realização de } \\
\text { investimento direto no mercado estrangeiro significa a ampliação da presença } \\
\text { de marcas nacionais junto a consumidores estrangeiros. }\end{array}$ \\
\hline
\end{tabular}

Fonte: Elaborado pela autora, 2006. 


\section{QUADRO 2}

MAPA DE ANÁLISE COMPARATIVA ENTRE AS CADEIAS AGROINDUSTRIAIS DO CAFÉ BRASILEIRA E ALEMÃ

\begin{tabular}{|c|c|c|c|}
\hline \multirow{2}{*}{ SEQ } & \multirow{2}{*}{ CRITÉRIOS } & ALEMANHA & BRASIL \\
\hline & & PESO 1 PESO 2 & PESO 1 PESO 2 \\
\hline 1 & Existência do elo na cadeia produtiva & & \\
\hline 2 & $\begin{array}{l}\text { Proximidade do suprimento de café verde com a } \\
\text { unidade de industrialização }\end{array}$ & & \\
\hline 3 & $\begin{array}{l}\text { Disponibilidade de tecnologia para modernização de } \\
\text { plantas industriais }\end{array}$ & & \\
\hline 4 & $\begin{array}{l}\text { Disponibilidade de tecnologia de descafeinização e } \\
\text { aromatização de café }\end{array}$ & & \\
\hline 5 & $\begin{array}{l}\text { Disponibilidade de tecnologia para envase e } \\
\text { companhias produtoras de embalagens }\end{array}$ & & \\
\hline 6 & Acesso à negociação em bolsa de mercadorias & & \\
\hline 7 & $\begin{array}{l}\text { Disponibilidade de laboratórios para realização de } \\
\text { controle de qualidade }\end{array}$ & & \\
\hline 8 & Prática de importação de matéria-prima & & \\
\hline 9 & Proximidade das áreas industriais com áreas portuárias & & \\
\hline 10 & $\begin{array}{l}\text { Instituições responsáveis pela governança da cadeia } \\
\text { produtiva }\end{array}$ & & \\
\hline 11 & $\begin{array}{l}\text { Capacidade de transferência de know-how para a } \\
\text { Organização Internacional do Café }\end{array}$ & & \\
\hline 12 & $\begin{array}{l}\text { Investimento direto da indústria nacional no mercado } \\
\text { externo }\end{array}$ & & \\
\hline
\end{tabular}

Fonte: Dados da pesquisa, 2006. 


\section{FIGURA 3}

\section{SÍNTESE GRÁFICA DO MAPA DE ANÁLISE COMPARATIVA}

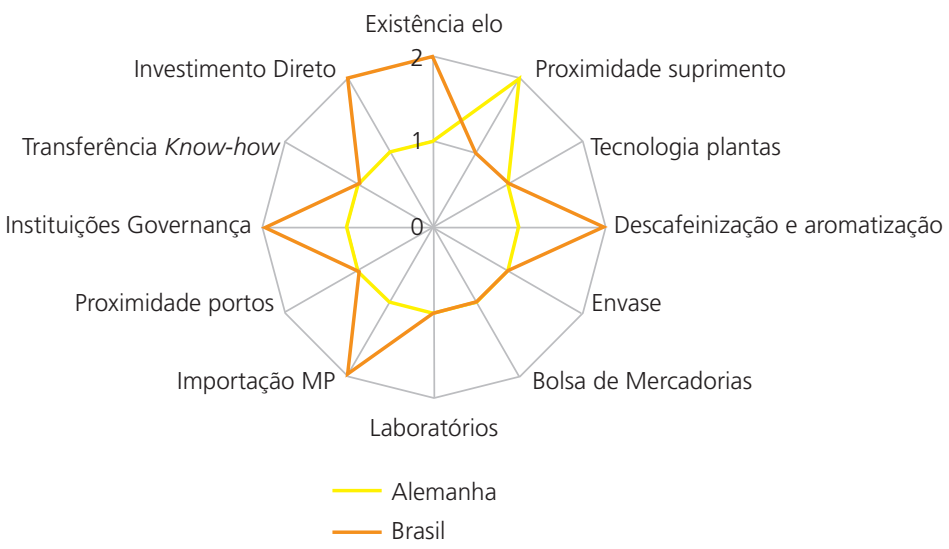

Fonte: Dados da pesquisa, 2006.

Conforme exposto, os sistemas agroindustriais de alimentos e fibras são nexos de contratos decorrentes do processo de minimização de custos de produção/distribuição e de transação (ZYLBERSZTAJN; FARINA, I994, p. 4). Isso significa que a indisponibilidade de alguns elos ou até mesmo de dispositivos legais pode contribuir para o aumento dos custos de transação e assimetria de informações, gerando incertezas. Por exemplo, no caso do fechamento de contrato internacional entre uma companhia brasileira e um comprador internacional, que vise a comercialização de cafés descafeinados ou com grãos de outras origens, as alternativas existentes seriam: ou a desistência do contrato por parte da companhia nacional, ou a terceirização da produção no mercado internacional. Isso aumentaria os custos para o atendimento do cliente, bem como os riscos relacionados à manutenção do controle de qualidade e atendimento do contrato nos prazos acordados.

Em relação à proximidade do suprimento de café verde com a unidade de industrialização, coube apenas à Alemanha a "desvantagem" de não ser produtora, como o Brasil o é. De acordo com Lambert e Cooper (2000, p. 69), todas as firmas participam de uma cadeia de suprimentos, desde a ligada à produção de materiais até o último consumidor. A relação entre essas, conforme os autores, depende do nível de proximidade entre suas atividades. Ao contrário do caso brasileiro, em que a proximidade das companhias torrefadoras com os produtores é grande (o Brasil é o maior produtor de café), a Alemanha demanda o estabelecimento de estratégias de captação junto a todos os países produtores de café, por meio de suas companhias especializadas no assunto, como a Newman Kaffee Group, que atua em 
mais de 25 países. As compras de café verde realizadas no mercado internacional favorecem uma externalidade positiva, que é a aquisição de produtos combinando qualidade e preço, o que, de modo geral, reduz o impacto do fato de o mercado alemão não ser produtor do grão. Aliás, verifica-se que essa é uma expertise que aparentemente não interessa à Alemanha, não só pela sua condição climática, mas pela sua experiência como mercado agregador de valor via industrialização, exportação de cafés industrializados e reexportação de matérias-primas. Não é à toa que é o primeiro comprador de café verde do Brasil, e o maior exportador de café industrializado do mundo.

Quanto à disponibilidade de tecnologia para modernização de plantas industriais, ambos os países possuem companhias especializadas na produção de equipamentos, compatíveis com as exigências do mercado internacional. A Probat, uma das referências mundiais na produção de tecnologia para companhias de torrefação e solubilização, possui plantas industriais instaladas nos dois países. Ainda se pode citar as alemãs Bosh e Neuhaus Neotec e a brasileira Cia. Lilla. O mesmo já não se pode dizer quando se trata da disponibilidade de tecnologia de descafeinização e aromatização de café. Considerando a análise entre Brasil e Alemanha, somente o mercado alemão possui a referida tecnologia de descafeinização, que se constitui na retirada da quase totalidade de cafeína existente no grão do café. Como visto anteriormente, no caso da aromatização para café, o Brasil já possui companhias que produzem aromatizantes para a indústria de alimentos, o que torna uma barreira tecnológica relativamente factível de romper.

Em relação ao acesso à negociação em bolsa de mercadorias e disponibilidade de laboratórios para realização de controle de qualidade, ambos os países têm igualdade de condições competitivas, embora possam existir algumas variações em termos de tecnologia laboratorial, principalmente.

Conforme visto no aporte teórico, a proximidade entre os agentes, combinada pelo nexo de contratos, gera a elevação do nível de competitividade do mercado e, por conseguinte, maior demanda por inserção de tecnologias e criação de salvaguardas e barreiras à entrada de concorrentes (COASE, I99I; WILLIAMSON, I983, I989, I991a, I991b, I996, 2000, 2005). A disponibilidade da tecnologia de descafeinização e aromatização de café justifica-se no Brasil, em função da sua gradativa inserção no mercado internacional de cafés industrializados, da necessidade de ampliação do portfólio de produtos a serem oferecidos aos consumidores estrangeiros, e, sem deixar de citar aqui, o próprio mercado nacional, que passa por transformações profundas, em relação à sua compreensão sobre o que é qualidade do café (FREITAS, 2006). Isso se aplica também à disponibilidade de laboratórios, para o controle de qualidade dos produtos, em virtude da maior confiabilidade das informações geradas. 
A prática de importação de matéria-prima, entretanto, é utilizada apenas pela Alemanha, o que gera vantagem competitiva e comparativa em relação ao Brasil quando se trata da capacidade de atendimento a mercados consumidores exigentes, em termos de variações de aromas e sabores do café. Além da importação de café verde, o mercado alemão também importa café industrializado, bem como realiza reexportação de café verde e café industrializado. O mercado brasileiro não pratica a importação de cafés verdes, embora importe um volume ainda pouco representativo de café industrializado.

Autores como Rocha (2002), Woods (200I), Coase (I99I) e Williamson e Winter (I99I) expõem que a orquestração das regras do jogo e interesses nacionais realizada pelas instituições assume importante papel no que diz respeito ao estabelecimento de acordos bilaterais e multilaterais, além de ser responsável pela otimização de capacidades em relação à diplomacia, assistência técnica, administração de tratados, acompanhamento de polícias comerciais entre outros.

Nesse sentido, verifica-se que a prática da importação de café no Brasil depende fundamentalmente de um acordo de cavalheiros entre os elos de industrialização (torrefação e solúvel) e o elo produtor. Tal acordo auxiliará na definição de regras claras, inclusive de cunho fitossanitário, de alçada do Ministério da Agricultura, Pecuária e Abastecimento, para que a prática seja realizada no País, embora já exista aparato legal consolidado tratando da permissividade dessa modalidade comercial internacional por parte de companhias brasileiras.

Em relação à proximidade das áreas industriais com áreas portuárias, a Alemanha possui maior vantagem; boa parte dos seus pólos industriais de café está situada em Hamburgo e Bremen, suas duas principais áreas portuárias. Contudo, levadas em consideração as dimensões continentais do Brasil, as regiões brasileiras que mais detêm áreas produtoras e industriais de cafés estão também situadas próximas a zonas portuárias, como Santos, Rio de Janeiro e Vitória. A disponibilidade de infra-estrutura para o escoamento da produção, especialmente para o mercado internacional, contribui diretamente para a redução de assimetrias de informações, custos de transação, influenciando na elevação do nível de confiança dos compradores em relação aos fornecedores nacionais e, respectivamente, na elevação da freqüência da aquisição de ativos (COASE, I99I; WILLIAMSON, 1983; 1989, 1991a, 1991b, 1996, 2000, 2005).

Quanto às instituições responsáveis pela governança da cadeia produtiva, a Alemanha tem uma vantagem sobre o Brasil, por possuir uma única instituição que congrega praticamente todos os agentes que atuam em sua cadeia produtiva: a Deutscher Kaffeeverband. Enquanto no Brasil, mesmo se considerando as dimensões continentais e colocando à parte os sindicatos patronais sediados por município produtor, as pequenas associações de produtores rurais, podem-se 
listar quatro grandes instituições brasileiras (Abic, Abics, Cecafé e CNC), que concorrem para a formação do órgão máximo da cafeicultura nacional que é o Conselho Deliberativo da Política do Café (CDPC). Esse último tem como papel servir de foro para estabelecimento de consensos de interesses entre os agentes institucionais e representantes setoriais, visando criar condições para o desenvolvimento. A pluralidade, considerando a análise, não é benéfica para a cadeia agroindustrial do café brasileira. Como visto, a prática de importação de café no Brasil ainda não está consolidada em virtude de longo processo de negociação entre os setores representantes dos produtores e dos industriais de café.

Em relação à capacidade de transferência de know-how para a Organização Internacional do Café, ambos os países são difusores de regras, e o Brasil tem atuação mais destacada, principalmente em relação a programas de qualidade, educação e promoção para o consumo, além do programa café e saúde, que difunde o café como bebida nutracêutica. Conforme visto no aporte teórico, a intensa evolução tecnológica registrada ao longo do último século provocou mudanças profundas no comportamento de indivíduos, firmas, instituições e nações, dado o maior fluxo de informações, organização da escala da produção (global) e, principalmente, a interação entre redes empresariais. Essas redes geram, de acordo com Claro (2004, p. I7), importantes implicações no relacionamento entre compradores e fornecedores, em função da relação direta com o desenvolvimento dos capitais humano e social. Além do impacto que as ações das instituições produzem no mercado interno, verifica-se que, dependendo do sucesso dessas mesmas ações, externalidades positivas são geradas, passando, dessa maneira, a se caracterizarem como regras do jogo em nível global. No caso do café, a transferência de experiências bem-sucedidas de um país para outros, via a OIC, é preponderante, em função da necessidade da elevação do consumo per capita, tanto em nível global, quanto em nível local, em mercados domésticos de países produtores, que na sua grande maioria são economicamente dependentes da cafeicultura. A OIC, nesse caso, funciona como "gerente" da rede de relações sociais que congrega 72 países produtores.

Por último, tem-se o investimento direto da indústria nacional no mercado externo. A cadeia agroindustrial do café alemã tem maior expertise, principalmente por meio de sua tradicional companhia, a Melitta, que atua inclusive no Brasil. No caso brasileiro, ainda não se registram companhias de capital nacional atuando além-fronteira, por meio de uma planta industrial instalada em território estrangeiro. O único caso registrado é o da Café Chocolat, que possui duas cafeterias instaladas na China, formadas da aliança estratégica entre uma empresa belga e uma cooperativa brasileira de cafeicultores. 


\section{CONSIDERAÇÕES FINAIS}

O que torna a Alemanha melhor do que o Brasil em termos de desempenho internacional no mercado de cafés com maior valor agregado? Foco em uma forte ação estratégica de mercado das empresas, coordenada por uma também forte governança institucional. O sistema agroindustrial do café brasileiro, em território nacional, é um dos mais organizados; entretanto, sua ação internacional mais contundente está centrada na produção e exportação de cafés verdes. Esse é o grande negócio brasileiro. Transitar desse contexto para um contexto de exportador de café industrializado significa um longo caminho a percorrer, não apenas pela necessidade de completar o parque industrial nacional com companhias de descafeinização e aromatizantes para café, mas também pela modernização da legislação do setor, favorecendo a importação de cafés. Outrossim, é preciso criar maior coesão entre interesses setoriais, visando o aumento da competitividade internacional brasileira, inclusive por meio da maior capitação e injeção de recursos no comércio exterior, com a internacionalização de companhias nacionais. Por meio do estudo, fica claro que parte do segredo alemão está na coordenação setorial realizada por uma única instituição e no poder econômico das suas empresas, multinacionais, diga-se de passagem.

\section{REFERÊENCIAS}

ASSOCIAÇÃO BRASILEIRA DA INDÚSTRIA DE CAFÉ. Disponível em: <http://www.abic.com. br>. Acesso em: I8 jul. 2006.

ASSOCIAÇÃO COMERCIAL DE SANTOS. Disponível em: <http://www.acs.com.br>. Acesso em I8 jul. 2006.

BARDIN, L. Análise de Conteúdo. Lisboa: Edições 70, 2000. 228 p.

BECHTEL, C.; JAYARAM, J. Supply chain management: uma perspectiva estratégica. Logística Moderna, Alcochete, n. 56, abr. I998.

CASTELLS, M. A sociedade em rede. São Paulo: Paz e Terra, I999, p. II9.

CENTRO DE INTELIGÊNCIA DO CAFÉ. Disponível em: <http://www.centrodeinteligenciadocafe. org.br>. Acesso em: I8 jul. 2006.

CENTRO DO COMÉRCIO DO CAFÉ DE MINAS GERAIS. Disponível em: <http://www.cccmg. com.br>. Acesso em: I8 jul. 2006.

CENTRO DO COMÉRCIO DO CAFÉ DO RIO DE JANEIRO. Disponível em: <http://www.cccrj. com.br>. Acesso em: I8 jul. 2006.

CENTRO DO COMÉRCIO DO CAFÉ DE VITÓRIA. Disponível em: <http://www.cccv.com.br>. Acesso em: I8 jul. 2006.

CLARO, D. P. Managing business networks and buyer-supplier relationships: how information obtained from business network affects trust, transaction specific investiments, collaboration and performance in the Dutch Potted an Flower Industry. Thesis. Wageningen University and Research Center, Netherlands, 2004. I95 p. 
CLEGG, S. R.; HARDY, C. Introdução: organização e estudos organizacionais. In: CLEGG, S. R.; HARDY, C.; NORD, W. R. Handbook de estudos organizacionais: modelos de análise e novas questões em estudos organizacionais. Organizadores da edição brasileira Miguel Caldas, Roberto Fachin e Tânia Fischer. São Paulo: Atlas, I998. v. I, p. 27-57.

COASE, R. H. The institutional structure of production. Genebra: The Nobel Foudantion, I99I. CONSELHO DOS EXPORTADORES DE CAFÉ DO BRASIL. Disponível em: <http://www.cecafe. com.br>. Acesso em: I8 jul. 2006.

CONSELHO NACIONAL DO CAFÉ. Disponível em: <http://www.cncafe.com.br>. Acesso em: ı8 jul. 2006.

COOPER, M. C.; LAMBERT, D. Issues in supply chain management. International Marketing Management, Gloucestershire, n. 29, p. 65-83, 2000.

COOPER, M. C.; LAMBERT, D.; PAGH, J. Supply chain management: more than a new name for logistics. International Journal of Logistics Management, Bingley, v. 8, n. I, p. I-I3, I997.

COUGHLAN, A. T. et al. Canais de marketing: estrutura e funções. In: COUGHLAN, A. T. et al. Canais de marketing e distribuição. 6. ed. Porto Alegre: Bookman, 2002, p. 19-38.

DEUTSCHE WELLE. Cartas geográficas. Disponível em: <http://www.dw-world.de/brazil>. Acesso em: 27 ago. 2004 .

DEUTSCHER KAFFEEVERBAND. Disponível em: <http://kaffeeverband.de>. Acesso em: i8 jul. 2006.

FEDERAÇÃO EUROPÉIA DO CAFÉ. Contrato europeu do café. Disponível em: <http://www.eca. com>. Acesso em: 30 set. 2004 .

FLORIANI, C. G. Café, a certificação é o caminho. Agrotec: Caderno Técnico, Belo Horizonte: IMA, n. I, 2000. 20 p.

FREITAS, M. L. G. Inserção internacional de empresas de cafés industrializados do Brasil: um estudo multicasos, 2006. I74 p. Dissertação (Mestrado)-Universidade Federal de Lavras, Lavras, Minas Gerais, 2006.

GRANOVETTER, M. Business Group. In: SMELSER, J. N. e SWEDBERG, R. The handbook of economic sociology. New Jersey: Princenton University Press, I994.

HARRISON, R. W.; KENNEDY, P. L. A neoclassical economic and strategic management approach to evaluating global agribusiness competitiveness. Lousiana Agricultural Experiment Station. Lousiana, v. 7, n. I, p. I4-25, I997.

INTERNATIONAL COFFEE ORGANIZATION. Disponível em: <http://www.ico.org>. Acesso em: 18 jul. 2006.

JOHANSON, J.; VAHLNE, J. E. The internationalization process of the firm: a model of knowledge development and increasing foreign market commitments. Journal of International Business Studies (pre-I986), p. 23-32, Spring, I997.

LAZZARINI, S. G.; CHADDAD, F. R.; COOK, M. L. Integrating supply chain and network analyses: the study of netchains. Chain and network science, Wageningen, v. I, n. I, p. 7-22, 200 I.

MACHADO, R. T. M. Tecnologia da informação e competitividade em sistemas agroindustriais: um estudo exploratório. Revista Brasileira de Agroinformática, Campinas, v. I, n. I, p. 66-76, I998.

Rastreabilidade, tecnologia da informação e coordenação de sistemas agroindustriais, 2000.

Tese (Doutorado em Administração)-Universidade de São Paulo, São Paulo, 2000. 
MACHADO, R. T. M. Estratégia e competitividade das organizações agroindustriais. Lavras: UFLA/ FAEPE, 2005. $65 \mathrm{p}$.

MINISTÉRIO DA AGRICULTURA, PECUÁRIA E ABASTECIMENTO. Instrução Normativa ํㅡㅇ, de II de junho de 2003. Dispõe sobre o padrão mínimo de qualidade do café verde comercializado no país. Disponível em: <http://www.agricultura.gov.br>. Acesso em: 4 set. 2008.

MINISTÉRIO DO DESENVOLVIMENTO, INDÚSTRIA E COMÉRCIO EXTERIOR. Radar comercial: análise de mercados e produtos. Disponível em: <http://radarcomercial.desenvolvimento.gov. br>. Acesso em: II ago. 2004.

MINISTÉRIO DO DESENVOLVIMENTO, INDÚSTRIA E COMÉRCIO EXTERIOR. Disponível em <http://www.desenvolvimento.gov.br>. Acesso em: I8 jul. 2006.

OXFAM INTERNATIONAL. Mugged: poverty in your coffee cup. Londres: Oxfam International, 2002.

PORTER, M. E. A análise estrutural de indústrias. In: PORTER, M. E. Estratégia competitiva: técnicas para análise de indústrias e da concorrência. Rio de Janeiro: Campus, I986, p. 22-47.

A cadeia de valores e a vantagem competitiva. In: PORTER, M. E. Vantagem competitiva: criando e sustentando um desempenho superior. Rio de Janeiro: Campus, I989, p. 3I-53.

PRAHALAD, C. K.; HAMEL, G. The core competence of the corporation. In: FOSS, N. J. Resources, firms and strategies: a reader in the resource-based perspective. New York: Oxford University Press, I997, p. 235-256.

RIORDAN, M. H.; WILLIAMSON, O. E. Asset specifity and economic organization. International Journal of Industrial Organization, Amsterdam, v. 3, p. 365-378, I985.

ROCHA, A. A internacionalização das empresas brasileiras: estudos de gestão internacional. Rio de Janeiro: Mauad, 2002. 267 p.

WILLIAMSON, O. E. Organization form, residual claimants and corporate control. Journal of Law \& Economics, Chicago, v. 26, p. 25I-235, June I983.

Las instituciones económicas del capitalismo. México: Fondo de Cultura Económica/Economía Contemporánea, I989. 43I p.

Transaction cost economics. In: Handbook of industrial organization. Chapter 3. Londres, Elsevier Science Publishers, v. I, I989.

Comparative economic organization: the analysis of discrete structural alternatives. Administrative Science Quartely, São Francisco, v. 36, p. 269-296, I991a.

La naturaleza de la empresa: orígenes, evolución y desarrollo. México: Fondo de Cultura Económica, I99I. 32I p.

Economics and organization. California Management Rewiew, Berkeley, v. 38, n. 2, p. I3II44, winter 1996.

The new institutional economics: talking stock, looking ahead. Journal of Economic Literature, Vanderbuilt, v. 38, p. 595-6r3, Sept. 2000.

Economics of governance. Working Paper. Berkeley: University of California. Jan. 2005. 50 p. WOODS, M. International business: an introduction. New York: Palgrave, 200I. 304 p.

ZAJAC, E.; OLSEN, C. P. From transaction cost to transactional value analysis: implications for the study of interoganizational strategies. Journal of Management Studies, Oxford, v. 30, n. I, Jan. I993. 
ZAJAC, E.; OLSEN, C. P.; FARINA, E. M. M. Q. Strictly coordinated food-systems: exploring the limits of coasian firm. International Food and Agribusiness Management Review, v. 2, n. 2, p. 249265, 1999 .

Competitividade e organização de cadeias agroindustriais. Costa Rica: Instituto Interamericano de Cooperação para a Agricultura, I994. 62 p.

ZYLBERSZTAJN, D.; FARINA, E. M. M. Q. Strictly coordinated food-systems: exploring the limits of coasian firm. International Food and Agribusiness Management Review, College Station, v. 2, n. 2, p. 249-265, I999.

Competitividade e organização de cadeias agroindustriais. Costa Rica: Instituto Interamericano de Cooperação para a Agricultura, I994. 62 p.

\section{TRAMITAÇÃO}

Recebido em 8/12/2006

Aprovado em 16/7/2008 